\title{
Etiology and treatment in craniofacial fractures
}

${ }^{1}$ ENT and Oro-Maxillo-Facial Department, Constanta County Hospital

\begin{abstract}
Introduction. Facial trauma remains an important pathology in present days because of its effects. Facial deformities and functional alteration affect patient's life quality and his society reinsertion. First evaluation has to be thorough to avoid any secondary complications. This type of pathology involves a pluridisciplinary approach: ENT, OMF, neurosurgeon, plastic surgeon, intensive care doctor.

Healing implies complex biological process .A healed bone is capable to perform normal duties without titanium plates help. Osteosynthesis allows a faster and correct recovery.

Doctors need to possess profound knowledge with regard to anatomy and physiology and to be acquainted with the reconstructive methods used in craniofacial surgery.

Material and methods. This study evaluates craniofacial trauma patients who suffered different types of surgical interventions at the ENT Clinic and OMF Department of Constanta County Hospital since January the 1st 2013 until June the 1st 2017.

Results. The group involves 133 cases, both genders and all ages. These 2 elements play an important role in this pathology because of the fact that the vast majority of patients are young active males. The sex ratio in the
\end{abstract}

\section{Dan Laurentiu Miahil}

Emergency County Hospital,145 Tomis, Constanta, Romania email : drdan_laurentiu@yahoo.com study is $7: 1$.

In most of cases, craniofacial traumas appear after aggressions and car accidents.

The nose and mandibular are fractured in a higher percentage in comparison to other parts of facial structures.

Discussions. Important and sensitive structures located at this level increase the risk of possible important and definitive damages.

Keywords: Craniofacial trauma, ostheosynthesis, titanium plates

\section{Introduction}

Even though society has developed different methods to increase personal safety, craniofacial trauma still represents an important problem that affects present population. The importance of these kind of injuries is related to visible functional and aesthetic secondary effects. Minor lesions can result in important disabilities if the applied treatment is not the correct one.

The entire population can suffer different types of traumas but the most affected group age includes young active people [1].

The initial evaluation and diagnostic can be difficult because haematomas and oedema can hide the real level of extension.

Facial deformity secondary to trauma and disabilities have a negative impact on the patient's 
life and his social reinsertion. Minor facial scars have an important psychological impact.

The surgeon's target is to re-establish normal anatomical aspect and facial physiological functions. The surgical treatment is guided by the doctor's medical judgment, should be adapted to the severity of the injury, and associated lesions. The recovery needs to be as short as possible with results maintained for the rest of the patient's life. The doctor needs to be acquainted with the reconstructive methods in craniofacial area using conservative and interventional methods in order to obtain the best results [2].

Developing the modern techniques has determined a dramatic improvement [2].

Fracture healing implies complex biological processes. The fracture can be considered cured when the bone is resuming all the functions and it is capable to resist physiologic forces without the help of the plates and screws [3].

Craniofacial trauma stands at the border of different specialities like: ENT, OMF, Ophthalmology, Neurosurgery, Plastic surgery and Intensive Care which allows to achieve correct diagnostic and treatment. Managing these type of injuries implies knowing local anatomy and physiology because important and sensible structures are located at this level. Here lies the organism command centre. The skull cavities contain organs that are controlling all the functions and sensitive structures for smell, taste, sight, hearing and balance. They also represent the way in for digestive and respiratory system [4].

This pathology has a high frequency among general population regarding age group and sex. The object of this study is to determine the main causes and pathological mechanisms, the degree of implication of different craniofacial regions and the type of surgical interventions required to obtain the best results.

\section{Material and methods}

The craniofacial trauma patients who suffered different types of surgical interventions at the ENT Clinic and OMF Department of Constanta County Hospital since January the 1st 2013 till June the 1st 2017 are the object of this study.

The group involves 133 cases.

To establish the correct diagnostic and the degree of injury the patients were evaluated by ENT and OMF specialists. Imagistic exams implied plain radiographies, MRI's and CT's.

\section{Results}

The group involved a number of 17 females, representing $12,78 \%$ and 116 males, representing $87,21 \%$, sex ratio is $7: 1$.(Figure 1 )

This can be the result of different types of activities, associated with risks, performed by the male population. Also men can be more aggressive.

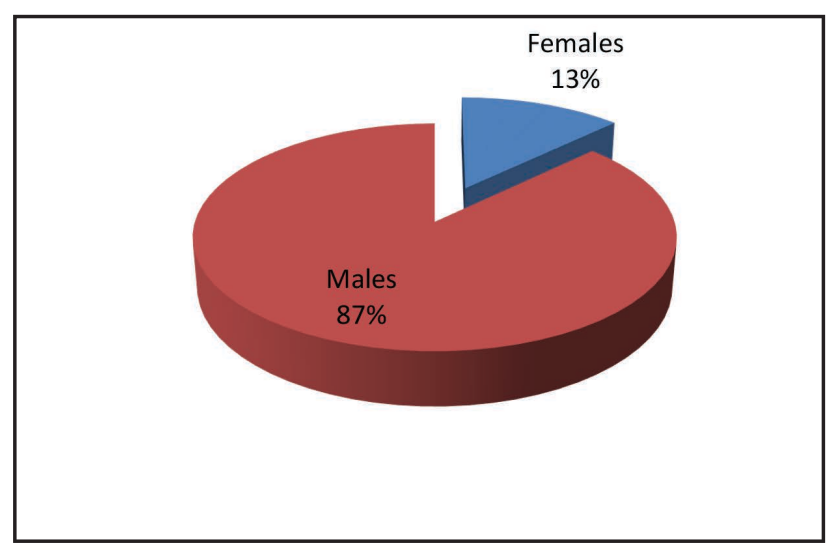

Figure1 Gender distribution

The age distribution evidence that between 0 and 20 years were 27 cases representing 20,3\%, between 20 and 40 years old there were 63 cases( $47,36 \%)$. From 40 to 60 there were $23 \operatorname{cases}(17,29 \%)$ 
and after 60 years 20 cases $(15,03 \%)$. The majority of traumas appeared in the young active population and it can have repercussions on society from an economical point of view (Figure 2)

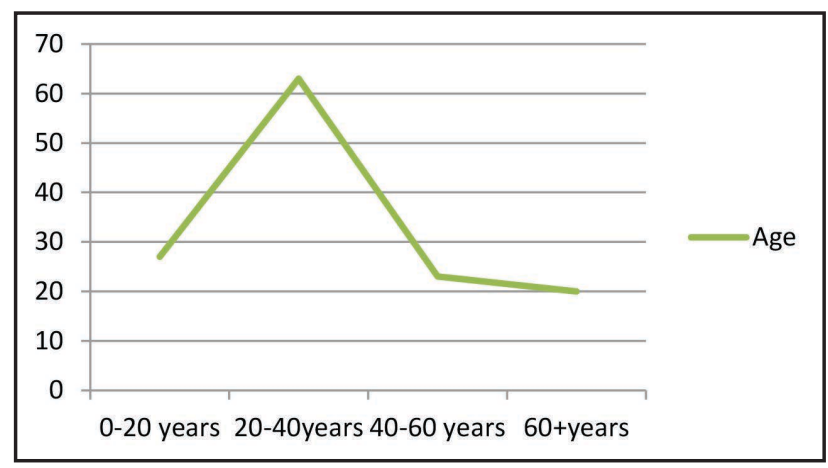

Figure 2 Age distribution

An evaluation of the injury mechanism shows that most cases appeared after agressions, $79,69 \%$ and car injuries, $8,27 \%$.Looking at the age of the majority of persons who suffered an injury we see an association between age and life style due to the fact that teens and young adults can be more rebellious and they disregard the common boundaries.(Table I)

Table I Mechanism of injury

\begin{tabular}{|l|l|l|}
\hline Mechanism of injury & Number & Percentage \\
\hline 1.Agressions & 106 & $79,69 \%$ \\
\hline 2.Car injuries & 11 & $8,27 \%$ \\
\hline $\begin{array}{l}\text { 3Falling down from the same } \\
\text { level }\end{array}$ & 6 & $4,51 \%$ \\
\hline 4.Falling from high ground & 2 & $1,5 \%$ \\
\hline 5.Sport injuries & 2 & $1,5 \%$ \\
\hline 6.Work injuries & 3 & $2,25 \%$ \\
\hline 7.Accidental traumas & 3 & $2,25 \%$ \\
\hline
\end{tabular}

Year distribution evidence in 201331 cases which needed surgical treatment,36 and 37 cases in 2014 and 2015,25 cases in 2016 and 4 cases in 2017. We can see an improvement in this pathology in the last years(Figure 3)

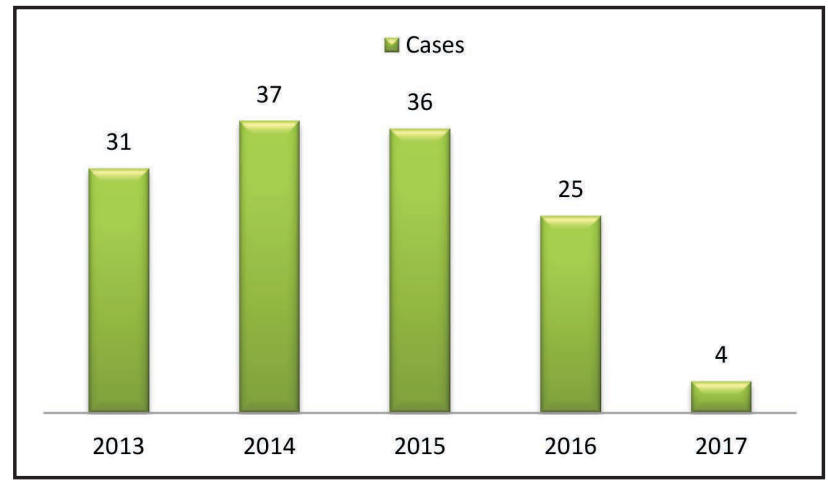

Figure 3 Years repartition

There were 95 cases with closed fractures representing $71,42 \%$ and 38 opened fractures representing $28,57 \%$.In opened fractures the soft tissues are destroyed and is created a breach. These cases have a higher risk of developing complications due to infections.

For reducing the fractures in cases of opened injuries, doctors used two kinds of approaches adapted for every patient:

- making new incisions using the hairline and other facial elements in order to hide the scars.

- using the existing scars appeared after the injury

For maintaining the fractured bones they used for osteosinthesis titanium plates of different dimensions adapted to each injury and titanium mesh. (Figure4)

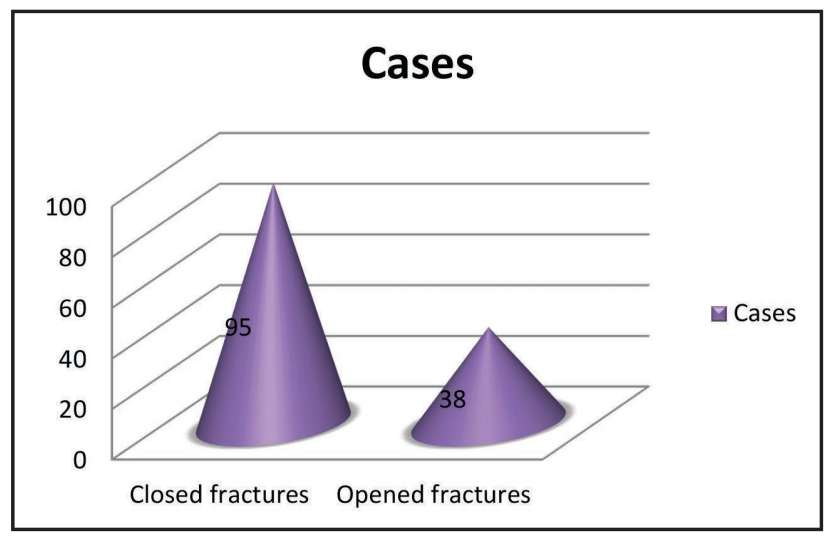

Figure 4 Types of 
We divided the craniofacial structures in 3 floors: superior, middle and inferior. The borders between these regions were the supraorbital rims and root of the nose separating the superior segment from the middle one and the border between the 2 dental arcades separating the middle floor from the inferior one.

The superior segment is represented by the frontal bone and sinuses.

The middle one is the most complex being formed by a number of bones and cavities.

The inferior floor is represented by the mandibula.

In 5 cases the superior floor suffered injuries which needed surgical treatment representing 4\%. In106 cases $(80 \%)$ the middle floor was affected and 22 cases (16\%) inferior floor. (Figure 5)

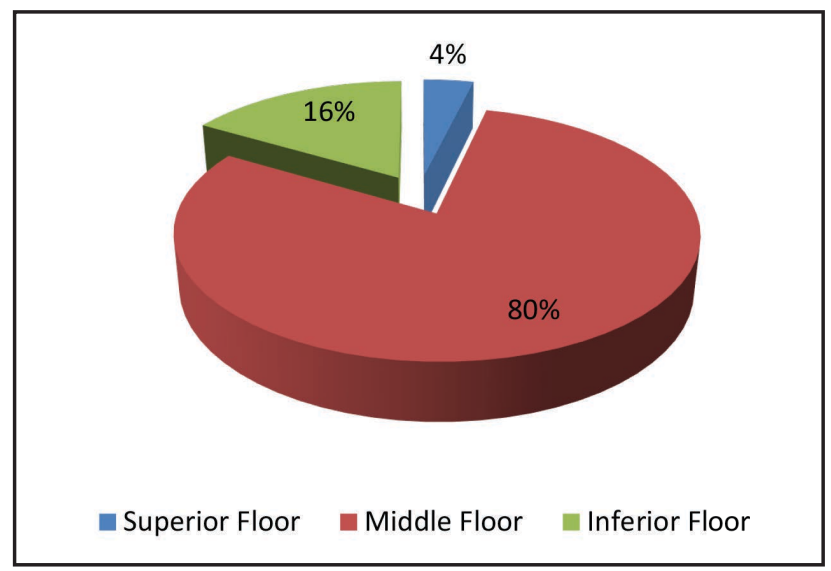

Figure 5 Floor Distribution

The next table is a thorough presentation of fractures and the structures affected by trauma. The nose is the principal segment. This can be explained by the fact that is placed in the centre of the face and is the most exposed part. The second element is the mandibula. (Table II)
Table II Fracture types

\begin{tabular}{|l|l|l|}
\hline Floors & Region & Number \\
\hline Superior Floor & \multicolumn{2}{|l|}{} \\
\hline \multicolumn{2}{|l|}{ Frontal Sinus } & 5 \\
\hline Middle Floor & Nasal Bones & 94 \\
\hline & Zygomatic Bone & 1 \\
\hline & TemporoZygomatic Arch & 1 \\
\hline & Orbital Fracture & 2 \\
\hline & Maxillary Fracture & 2 \\
\hline & Cominuted Fracture & 4 \\
\hline & \\
\hline Inferior Floor(Mandible) & 9 \\
\hline & Angle & 17 \\
\hline & Body & 3 \\
\hline & Ramus & 1 \\
\hline & Condyle & 1 \\
\hline & Cominuted &
\end{tabular}

There were 27 cases of mandibular fractures: 20 cases of simple fractures(74\%),5 double fractures $(18,51 \%)$ and 2 cominuted fractures $(7,4 \%)$. The most important factors which influence the fracture patterns are the intensity and direction of the force. In addition, pre-existing pathological conditions play an important role. (Figure6)

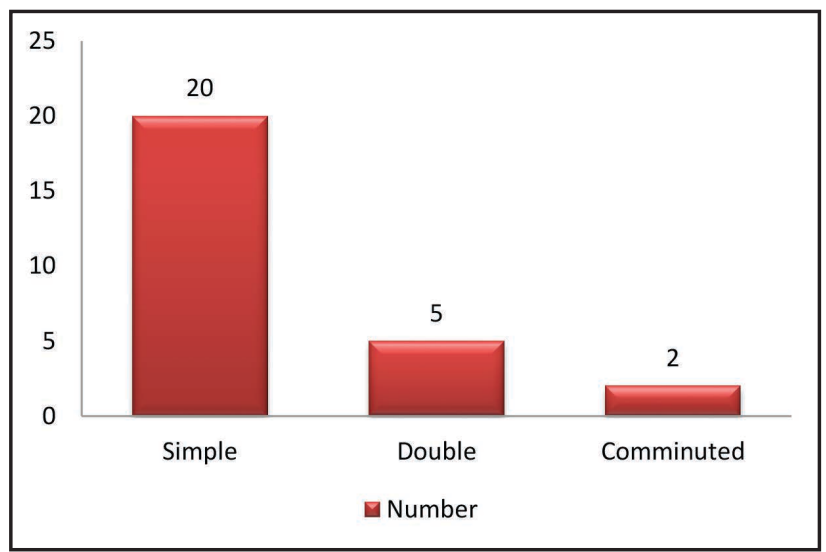

Figure 6 Mandibular fracture types

There were used two types of approach in these fractures:

- closed reduction using arch bars, bridle 
wires and intermaxillary fixation.

- opened reduction using titanium plates. Those are more complex interventions but have the advantages of a faster recovery of functions. (Figure7)

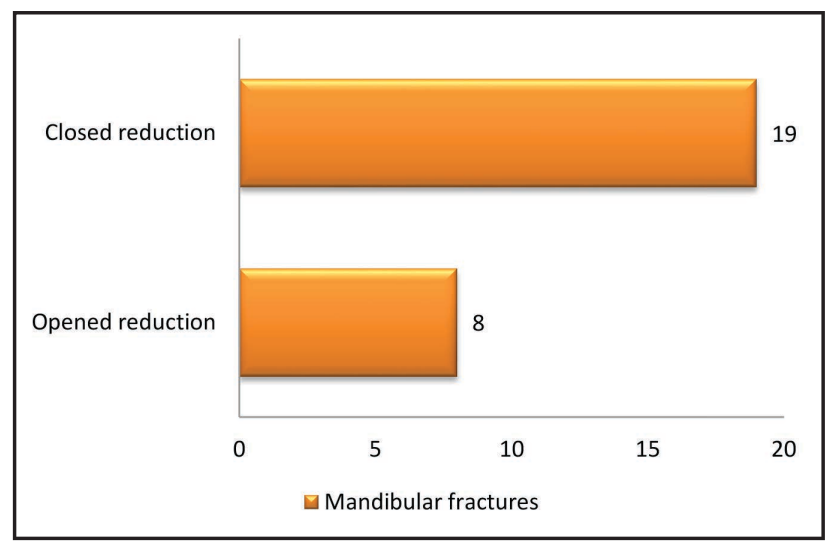

Figure 7.Mandibular fractures reduction type

\section{Discussions}

Despite medicine evolution and different techniques and materials used in present days for treating such types of injuries it still remains challenging for the doctors. Because of the location, even minor anatomic and functional dysfunction can play an important role in patient's life quality and his reinsertion in the society [1].

The materials used in case of ostheosintesis were titanium plates and meshes because they are biocompatible, resistant and elastic, with a small rate of rejection [2].

A healthy bone is able to perform normal duties without any additional help[3].

Important vascular and nervous structures are located in this body region. Traumas can associate with brain damage and can also affect respiratory and digestive system altering patients life [4].

Gender and age plays an important role in such traumas due to a more active and hazardous life in case of men, especially teenagers and young adults.

Aggressions and car accidents are the most common causes and can be linked with patient's age and gender.

The most common fracture with displacement is the nasal fracture because it is a prominent structure in the centre of the face and because of the fact that nasal bones are fragile. Mandibular fractures are the second most common and they influence speaking and eating altering patient's life quality $[5,6]$.

Such type of pathology needs a correct and complete primary evaluation using imagistic techniques and a pluridisciplinary approach to avoid overlooking some injuries which can develop important complications [7].

\section{References}

1. Perry, M. \& Holmes S. (2014). Manual of Operative Maxillofacial Trauma Surgery. Springer International Publishing, Swizerland (pp 3-12, 20-21, 33-37, 169-534)

2. Mathog, R. H., Shibuya, T. \& Carron M.A. (2012). Mathog's Atlas of Craniofacial Trauma. 2nd Edition, Wolters Kluwer (pp 3-24, 307-320, 337-475)

3. Thaller, S.R., Bradley, J.P. \& Garry, J.I. (2008). Craniofacial Surgery Informa Healthcare (pp 289-315)

4. Bucur, A. (2009). Compendiu de chirurgie oromaxilo-facială. Ed Q Med Publishing S.R.L, (pp 312-394)

5. Gârbea, S. (1985). Rinologie-Patologia nasului și a sinusurilor paranazale. Editura Ştiinţifică și Enciclopedică, București. (pp469-478, 165-183)

6. Fonseca, R. J., Walker, R., Powers, M.P. \& Barber, H.D. (2013). Oral\&Maxillofacial trauma Fourth Edition, Elsevier Inc. (pp239-250)

7. Ernst, A., Herzog, M. \& Seidl, R.O. (2006). Head and Neck Trauma-An Interdisciplinary Approach. Thieme Medical Publishers. (pp 2735, 69-90, 100-105, 112-119). 